\title{
Adubação potássica em cultivo protegido de pimentão sob sistema orgânico
}

\section{Potassium fertilization in protected cultivation of sweet pepper under organic system}

\author{
William Ralf Santos Costa ${ }^{1}{ }^{1}$; Pedro Henrique Máximo de Souza Carvalho ${ }^{(2}{ }^{2}$; Paulo Augusto da Costa \\ Pinto (D) $^{3}$
}

${ }^{1}$ Engenheiro Agrônomo pela Universidade do Estado da Bahia, Juazeiro, Bahia; (74) 988190250, ralfw20@gmail.com; ${ }^{2}$ Graduando em Engenharia Agronômica pela Universidade do Estado da Bahia, Juazeiro, Bahia; (87) 999727737, pedrocarvalho2008@ hotmail.com; ${ }^{3}$ Doutor e Professor Aposentado da Universidade do Estado da Bahia, Juazeiro, Bahia, pacostapinto@hotmail.com

A R T I G O

Recebido: 22/11/2018

Aprovado: 09/03/2019

\section{Palavras-chave:}

Capsicum annum

Fertilizantes potássicos

Ambiente protegido

Key words:

Capsicum annum

Potassic fertilizers

Protected environment

\begin{abstract}
R E S U M O
As hortaliças cultivadas em ambiente sombreado vêm ganhando mais espaços frente ao sistema de plantio em campo aberto, destaca-se o pimentão, por estar entre as dez culturas mais produzidas. Assim, objetivou-se avaliar a eficiência de fontes e fertilizantes potássicos na nutrição de plantas de pimentão (Capsicum annuum L.), sob sistema orgânico. O delineamento experimental utilizado foi em blocos casualizados, sendo utilizadas duas fontes de potássio: sulfato de potássio $(50 \%$ de $\mathrm{K})$ e cinza de madeira $(5,84 \%$ de $\mathrm{K})$ em seis blocos, com três plantas cada. O tratamento com cinza de madeira obteve maior desempenho quanto às seguintes variáveis: número de frutos por planta, massa média dos frutos, comprimento dos frutos, espessura de polpa, produtividade comercial. Quanto às variáveis químicas, a adubação com cinza de madeira obteve resultados superiores para sólidos solúveis, vitamina $\mathrm{C}$ e acidez titulável. Com base nos resultados obtidos, pode-se concluir que o tratamento com adubação com cinza de madeira foi promissor no tocante às características físicas e, apenas para o pH, obteve-se valores inferiores aos demais tratamentos. A utilização da cinza de madeira como fonte de nutrição de plantas de pimentão, resultou em uma maior produtividade comercial.
\end{abstract}

\section{A B S T R A C T}

\begin{abstract}
The vegetables grown in a shaded environment have been gaining more space in front of the open field planting system. Among the vegetables, it stands out the pepper, being among the ten most produced crops. The objective of this study was to evaluate the efficiency of potassium sources and fertilizers in the nutrition of pepper plants (Capsicum annuиm L.) under an organic system. The experimental design was a randomized complete block design, using two sources of potassium: potassium sulphate $(50 \% \mathrm{~K})$ and wood ash $(5,84 \%$ $\mathrm{K}$ ) and six blocks, each with three plants. ash yielded higher performance in relation to the following variables: number of fruits per plant, mean fruit mass, fruit length, pulp thickness, commercial productivity. With chemical variables, fertilization with wood ash yielded superior results for soluble solids, vitamin $\mathrm{C}$, and titratable acidity. On the basis of the results obtained, it can be concluded that the treatment with wood ash fertilization was promising regarding the physical characteristics and, for the $\mathrm{pH}$ only, lower values were obtained than the other treatments. use of wood ash as a source of nutrition for sweet pepper plants resulted in higher commercial productivity.
\end{abstract}

\section{INTRODUÇÃO}

As hortaliças cultivadas em ambiente sombreado vêm ganhando mais espaços frente ao sistema de plantio em campo aberto. Destacam-se em sistema de ambiente protegido: o pimentão, o tomate, o pepino, as folhosas (alface, rúcula, cheiro verde) e o moranguinho (ISHIKAVA; FIGUEIREDO, 2011). O pimentão é uma das dez culturas mais produzidas no Brasil (CNA, 2017).

Segundo Moraes et al. (2011), o cultivo de hortaliças em ambiente protegido tem sido cada vez mais utilizado, pois

\section{Revista Verde}

ISSN 1981-8203

Pombal, Paraíba, Brasil v. 14, n.2, abr.-jun, p.224-228, 2019

doi: 10.18378/rvads.v14i2.6134 
proporciona uma condição microclimática adequada para o desenvolvimento das culturas, reduzindo, principalmente, os efeitos nocivos da alta taxa de incidência da radiação solar e protegendo contra os extremos de temperatura. O uso de adubações orgânicas tende a suprir a necessidade nutricional de pimentão e hortaliças em geral, proporcionando uma elevação na produtividade e na qualidade dos frutos (SEDIYAMA et al., 2009; VIDIGAL et al., 2010).

Oliveira et al. (2009) afirmam o potencial de adubos orgânicos na melhoria da agregação do solo, especialmente porque influencia na infiltração do solo e na capacidade de retenção de água, bem como na drenagem, aeração, temperatura e penetração de raízes. A preocupação com o ambiente e qualidade de vida vem adicionando cada vez mais valor à agricultura orgânica. Esse modelo de produção tem crescido constantemente em função da procura cada vez maior por produtos sem resíduos químicos (NEGRETTI et al., 2010).

No sistema orgânico de produção é fundamental a nutrição da planta, pois plantas bem nutridas estão menos suscetíveis a pragas e doenças. Um dos elementos nutritivos mais importantes na nutrição de plantas e hortaliças é o potássio. Esse elemento atua na regulação osmótica e promove a manutenção do turgor nas células guardas, por meio da elevação do seu potencial osmótico, tornando possível a absorção de água por essas células (SOARES et al., 2015).

Segundo Uchôa et al. (2011), o elemento potássio tem sido utilizado na nutrição de plantas em diversos estudos, com o intuito de averiguar a sua relação com as características morfológicas das culturas e seus eventuais reflexos na produtividade. Com isso, o presente trabalho objetivou-se avaliar a eficiência de fontes e fertilizantes potássicos na nutrição de plantas de pimentão sob sistema orgânico de produção em ambiente protegido.

\section{MATERIAL E MÉTODOS}

$\mathrm{O}$ experimento foi desenvolvido na área experimental de produção orgânica da Universidade do Estado da Bahia (UNEB), Campus III, no Departamento de Tecnologia e Ciências Sociais (DTCS) no período de julho a novembro de 2015.

O local do experimento apresenta coordenadas geográficas: latitude $9^{\circ} 25^{\prime} 43^{\prime \prime} \mathrm{S}$, longitude $40^{\circ} 32^{\prime} 14^{\prime \prime} \mathrm{W}$, e altitude $384 \mathrm{~m}$. O clima da região, conforme de Köppen, é do tipo BSwh, ou seja, clima semiárido com precipitação anual de $380 \mathrm{~mm}$ a $760 \mathrm{~mm}$ e temperatura média anual do ar maior que $18{ }^{\circ} \mathrm{C}$.

O solo da área experimental foi classificado como Neossolo Flúvico. O experimento foi conduzido em uma área sob sombreamento, com tela do tipo chromatinet difusor $40 \%$. $\mathrm{Na}$ área reservada para o estudo, foi colhida uma amostra de solo para análise química, com profundidade de 0 a 20 , e encaminhada ao LASAC (Laboratório de Análises de solo, água e calcário) do DTCS/UNEB. O resultado da análise de solo da área experimental está disposto na Tabela 1.

Tabela 1. Análise química do solo da área experimental

\begin{tabular}{ccccccccccccc}
\hline $\mathrm{pH}$ & $\mathrm{C} . \mathrm{E}$ & $\mathrm{Ca}^{+2}$ & $\mathrm{Mg}^{+2}$ & $\mathrm{~K}^{+}$ & $\mathrm{Na}^{+}$ & $\mathrm{SB}$ & $\mathrm{Al}^{+3}$ & $\mathrm{H}+\mathrm{Al}^{+3}$ & $\mathrm{~T}$ & $\mathrm{~V}$ & $\mathrm{P}$ & M.O. \\
\hline $\mathrm{H}_{2} \mathrm{O}$ & $(\mathrm{dS} \mathrm{cm}$ & & & & & $\left(\mathrm{cmolc} \mathrm{dm}^{-1}\right)$ & & & & $(\%)$ & $\left(\mathrm{mg} \mathrm{dm}^{-3}\right)$ & $\left(\mathrm{g} \mathrm{kg}^{-1}\right)$ \\
\hline 6,30 & 0,01 & 1,23 & 0,17 & 0,48 & 0,07 & 1,95 & 0,00 & 0,80 & 2,75 & 70,90 & 49,00 & 5,82 \\
\hline
\end{tabular}

O sistema de irrigação adotado foi por gotejamento, sendo o manejo da irrigação baseado na evapotranspiração diária, quantificada pela estação meteorológica implantada no campus.

O delineamento experimental utilizado foi em blocos casualizados, sendo utilizadas duas fontes de potássio e uma testemunha: sulfato de potássio ( $50 \%$ de $\mathrm{K})$, cinza de madeira $(5,84 \%$ de $\mathrm{K})$ e a testemunha (sem aplicação de $\mathrm{K}$ ), com seis blocos e três plantas por bloco.

A hortaliça utilizada foi o pimentão (Capsicum annuum), cv. Supremo, e suas mudas foram produzidas em badejas de isopor, com noventa e seis células em substrato comercial a base de casca de pinus, sendo colocadas duas sementes por célula, mantidas em casa de vegetação por um período de 15 dias. O transplantio ocorreu após os 15 dias e adotou-se o espaçamento de $1,00 \mathrm{~m}$ entre linhas e 0,40 m entre plantas, sendo que a área de plantio tinham recebido a adubação de fundação com nitrogênio (torta de mamona) e com fósforo (fosfato natural de Gafsa), seguindo o manual de recomendação de adubação (IPA, 2008). Devido ao solo já conter teor satisfatório de potássio, não foi feita adubação de fundação com potássio, sendo feita apenas adubação de cobertura.

As colheitas foram realizadas aos 95, 114 e 130 dias após o semeio (DAS), sendo os frutos colocados em sacos plásticos identificados, transportados em caixas plásticas para o
Laboratório de Biologia do DTCS III, onde foram avaliadas as seguintes variáveis: número de frutos por planta; peso médio de fruto $(\mathrm{g})$; comprimento dos frutos $(\mathrm{mm})$; diâmetro dos frutos (mm); relação comprimento/diâmetro; espessura da poupa dos frutos $(\mathrm{mm})$; produtividade comercial $\left(\mathrm{t} \mathrm{ha}^{-1}\right)$; sólidos solúveis ( $\left.{ }^{\circ} \mathrm{Brix}\right) ; \mathrm{pH}$; vitamina $\mathrm{C}$ e acidez titulável (\% ácido cítrico). Os dados foram submetidos à análise de variância pelo software ASSISTAT 7.5 (SILVA, 2008) e ao teste de Tukey $(\mathrm{P}<0,05)$.

\section{RESULTADOS E DISCUSSÃO}

De acordo com a análise de variância, verificou-se efeito significativo em níveis de probabilidade, variando de 5 a $1 \%$ entre fontes de potássio para a variável número de frutos por planta, peso de fruto, comprimento de planta, diâmetro de fruto, relação comprimento/diâmetro, espessura da polpa, e produtividade (Tabela 2 ).

O tratamento com cinza de madeira possibilitou maior desempenho quanto as variáveis: número de frutos por planta $(28,75)$, massa média $(93,54 \mathrm{~g})$, comprimento $(130,71 \mathrm{~mm})$, espessura de polpa $(4,4 \mathrm{~mm})$ e produtividade comercial $(54,82 \mathrm{t}$ $\mathrm{ha}^{-1}$ ).

No tocante ao número médio de frutos por planta, os resultados evidenciam que o desenvolvimento das plantas de 
pimentão pode ser influenciado pelas fontes potássicas. Krolow et al. (2004) avaliando o desempenho do pimentão, sob adubação orgânica em ambiente protegido, obteve valores inferiores quando ao número de fruto por planta. Charlo et al.,
(2009) estudando diferentes híbridos de pimentão, observou uma variação de 16,94 a 21,64 frutos por planta, resultado semelhante ao encontrado no tratamento testemunha desse trabalho (tabela 2).

Tabela 2. Número de frutos (NF), peso de frutos (PF), comprimento de planta (C.P), diâmetro de fruto (D.F), relação comprimento/diâmetro (C.D), espessura da polpa (EP) e produtividade comercial (PC) de pimentão em cultivo protegido

\begin{tabular}{cccccccc}
\hline Tratamentos & N.F & P.F $(\mathrm{g})$ & C.P $(\mathrm{mm})$ & D.F $(\mathrm{mm})$ & $\begin{array}{c}\text { Relação C/D } \\
(\mathrm{mm})\end{array}$ & $\begin{array}{c}\text { E.P }(\mathrm{mm}) \\
\left.(\mathrm{t} \mathrm{ha})^{-1}\right)\end{array}$ \\
\hline Test. & $19,79 \mathrm{c}$ & $68,58 \mathrm{~b}$ & $106,08 \mathrm{~b}$ & $51,26 \mathrm{ab}$ & $2,09 \mathrm{~b}$ & $3,85 \mathrm{~b}$ & $32,11 \mathrm{~b}$ \\
CM & $28,75 \mathrm{a}$ & $93,54 \mathrm{a}$ & $130,71 \mathrm{a}$ & $53,92 \mathrm{a}$ & $2,46 \mathrm{a}$ & $4,40 \mathrm{a}$ & $54,82 \mathrm{a}$ \\
SP & $22,08 \mathrm{~b}$ & $72,87 \mathrm{~b}$ & $109,01 \mathrm{~b}$ & $48,58 \mathrm{~b}$ & $2,28 \mathrm{ab}$ & $3,73 \mathrm{~b}$ & $33,80 \mathrm{~b}$ \\
\hline Teste de F & $171,41 * *$ & $10,45 * *$ & $13,69 * *$ & $3,22 *$ & $5,04 * *$ & $5,32 * *$ & $60,87 * *$ \\
\hline CV $(\%)$ & 7,40 & 22,82 & 15,45 & 14,19 & 17,98 & 19,05 \\
\hline
\end{tabular}

Testemunha (Test); Cinza de Madeira (CM); Sulfato de Potássio (SP); * Significativo ao nível de 5\% de probabilidade; ** Significativo ao nível de $1 \%$ de probabilidade; ${ }^{\text {ns }}$ não significativo.

Conforme Oliveira et al. (2012), o número de frutos produzidos por planta pode apresentar uma relativa variação nos cultivos a depender do ciclo e manejo empregado, estando diretamente ligado ao rendimento da planta. Cavalcante (2008), avaliando o efeito da irrigação na produção de pimentão cv. Ikeda, obteve como resultado: 21,03 g para a variável peso e $57,3 \mathrm{~mm}$ para comprimento dos frutos, resultados inferiores aos encontrados neste trabalho.

Ribeiro et al. (2000), trabalhando com adubação orgânica na produção de pimentão, obtiveram resultados inferiores apenas para as variável peso médio e comprimento dos frutos, em relação a este trabalho.

A variável diâmetro do fruto da fonte cinza de madeira $(53,92 \mathrm{~mm})$ se diferenciou da fonte sulfato de potássio $(48,58$ $\mathrm{mm})$, mas não apresentou resultados significativos em relação à testemunha $(51,26 \mathrm{~mm})$, sendo que a deficiência de potássio normalmente reduz o crescimento e o desenvolvimento das plantas, retardando a frutificação e produzido frutos de menor tamanho e com menor intensidade de cor (ERNANI et al., 2007).

A relação comprimento/diâmetro do fruto da fonte cinza de madeira apresentou o maior valor, embora não tenha diferido significativamente da fonte sulfato de potássio. Esta relação está ligada ao formato do fruto, sendo que os frutos de formato quadrado, apresentam relação comprimento/diâmetro mais próxima de 1, e frutos mais alongados, sejam eles dos grupos retangular ou cônico, apresentam relação mais distante de 1 (CHARLO et al., 2009).
Observou-se que, para espessura de polpa, houve diferença significativa entre os tratamentos, com média de $4,40 \mathrm{~mm}$ para o tratamento com cinza de madeira, $3,85 \mathrm{~mm}$ para testemunha e 3,73 para o tratamento sulfato de potássio. Frizzone et al., (2001), em seus estudos com a cultura do pimentão do subgrupo amarelo, verificaram médias semelhantes de espessura de polpa, variando de 2,5 a 5,6 mm. Para Vargas et al., (2013) frutos que apresentam polpa mais espessa, são mais resistentes ao transporte, têm maior duração pós-colheita e maior rendimento em massa, além de sua maior preferência pelo mercado.

A maior produtividade comercial $\left(54,82 \mathrm{t} \mathrm{ha}^{-1}\right)$, obtida no tratamento com adubação por cinza de madeira, demostra a viabilidade agronômica que possui uma fonte orgânica para produção, sendo capaz de suprir a exigência nutricional da planta, resultando em frutos com características desejáveis ao mercado.

Segundo Filgueira (2008), a produtividade média obtida para o pimentão varia de 40 a $60 \mathrm{t} \mathrm{ha}^{-1}$ em campo aberto, e com a introdução de novos híbridos e o cultivo em ambiente protegido, tende a elevar-se, alcançando produtividades maiores. Albuquerque et al. (2011), avaliando com o efeito da irrigação e doses de potássio na cultura do pimentão cultivado em solo, alcançaram uma produtividade média de $18,58 \mathrm{t} \mathrm{ha}^{-1}$, resultado inferior aos encontrados nesse estudo.

Pode-se observar na Tabela 3 uma interação significativa entre as fontes potássicas, tendo sido avaliados os valores médios de sólidos solúveis, $\mathrm{pH}$, vitamina $\mathrm{C}$ e acidez titulável.

Tabela 3. Sólidos solúveis (S.S), pH, vitamina C e acidez titulável em frutos de pimentão conforme a adubação com cinza de madeira ou com sulfato de potássio

\begin{tabular}{ccccc}
\hline Tratamentos & S.S $\left({ }^{\circ} \mathrm{Brix}\right)$ & $\mathrm{pH}\left(\mathrm{H}_{2} \mathrm{O}\right)$ & Vitamina C & Acidez Titulável \\
\hline Test. & $5,84 \mathrm{~b}$ & $4,37 \mathrm{a}$ & $55,66 \mathrm{ab}$ & $0,34 \mathrm{ab}$ \\
$\mathrm{CM}$ & $6,50 \mathrm{a}$ & $4,00 \mathrm{~b}$ & $58,72 \mathrm{a}$ & $0,40 \mathrm{a}$ \\
$\mathrm{SP}$ & $5,87 \mathrm{~b}$ & $4,47 \mathrm{a}$ & $50,49 \mathrm{~b}$ & $0,23 \mathrm{~b}$ \\
\hline Teste de F & $5,39^{* *}$ & $10,70 * *$ & $5,26 * *$ & $0,58 *$ \\
\hline $\mathrm{CV}(\%)$ & 12,97 & 8,83 & 16,16 & 10,80 \\
\hline
\end{tabular}

Testemunha (Test.); Cinza de Madeira (CM); Sulfato de Potássio (SP); *Significativo ao nível de $5 \%$ de probabilidade; **Significativo ao nível de $1 \%$ de probabilidade; ns não significativo.

As plantas adubadas com cinza de madeira apresentaram frutos com maior média de sólidos solúveis $(6,50)$ se diferenciando, significativamente, em relação à fonte sulfato de potássio $(5,87)$ e em comparação à testemunha $(5,84)$. Os 
resultados obtidos para sólidos solúveis foram próximos aos verificados por Charlo et al. (2009), trabalhado com cultivo de híbridos de pimentão. Em pesquisa realizada com pimentão, Nannetti (2001) descreve que a adubação potássica proporciona aumentos nos teores de sólidos solúveis pela função que esse nutriente desempenha como, por exemplo, na translocação de fotossintatos e na ativação de diversas enzimas.

A fonte cinza de madeira apresentou a menor média de $\mathrm{pH}$ $(4,00)$ sendo, portanto, seus frutos mais ácidos do que os encontrados com a fonte sulfato de potássio e testemunha. $\mathrm{Na}$ presente pesquisa, os valores de $\mathrm{pH}$ variaram de 4,00 até 4,47. Esses valores estão próximos aos observados por Factor (2003), que verificou em frutos maduros de pimentão da cultivar Margarita, cultivada em diferentes substratos e soluções nutritivas, valores de $\mathrm{pH}$ na faixa de 4,95 a 5,04. Porém, estão abaixo da faixa descrita por Abreu et al. (2012), que variou entre 5,0 e 6,5

A variável vitamina $\mathrm{C}$ e acidez titulável, no tratamento com adubação por cinza de madeira, diferenciaram-se significativamente em relação à testemunha e ao tratamento com sulfato de potássio.

Os valores de acidez titulável foram superiores aos encontrados por Santos (2015), que ao trabalhar com o híbrido Lucia $\mathrm{R}$, encontrou um valor máximo de acidez igual a 0,29.

As respostas obtidas em ambiente sombreado se devem à menor incidência de radiação solar direta, que permitiu que os estômatos ficassem abertos por maior período de tempo, permitindo que o potássio pudesse aumentar a taxa fotossintética da planta, reduzindo a velocidade de respiração, aumentando a síntese de proteínas, fazendo a manutenção do potencial osmótico das células (CASTRO, 2005).

\section{CONCLUSÕES}

A adubação com cinza de madeira como fonte de potássio é promissora no cultivo protegido de pimentão, pois possibilita elevada produtividade comercial com plantas e frutos apresentando boas características físicas e químicas.

\section{REFERÊNCIAS}

ABREU, M. G.; DIAS, R. S.; ABREU, C. A.; GONZALEZ, A. P. Reavaliação dos critérios constantes na legislação brasileira para análises de substratos. Bragantia, v.71, n. 1, p.106-111, 2012 .

ALBUQUERQUE, F. S.; SILVA, E. F. F.; ALBUQUERQUE FILHO, J. A. C.; NUNES, M. F. F. N. Crescimento e rendimento de pimentão fertirrigado sob diferentes lâminas de irrigação e doses de potássio. Revista Brasileira de Engenharia Agrícola e Ambiental, v.15, n. 7, p.686-694, 2011.

CASTRO, P. R. C.; KLUGE, R. A.; PERES, L. E. P. Manual de Fisiologia Vegetal. 1. ed. São Paulo - SP: Editora agronômica Ceres LTDA, 2005. 650 p.

CAVALCANTE, R. R. R. Diferentes lâminas de água e doses de nitrogênio na produção de pimentão. 2008. 58 f. Dissertação
(Mestrado em Agronomia) - Departamento de Engenharia Agrícola, Universidade federal do Ceará, Fortaleza. 2008.

CHARLO, H. C. O.; CASTOLDI, R.; FERNANDES, C.; VARGAS, P. F.; BRAZ L. T. Cultivo de híbridos de pimentão amarelo em fibra da casca de coco. Horticultura Brasileira, Brasília, v. 27, n. 2, p. 155-159, 2009.

ERNANI, P. R.; ALMEIDA, J. de A.; SANTOS, F, C. dos. Potássio. In: NOVAIS, R. F.; ALVAREZ V., V. H.; BARROS, N. F.; FONTES, R. L. F.; CANTARUTTI, R. B.; NEVES, J. C. L. (Eds.). Fertilidade do solo. 1. Ed, Viçosa: UFV, 2007. p. 551 $-594$.

FACTOR, T. L. Utilização do efluente de biodigestor no cultivo de pimentão em substratos, sob ambiente protegido. $2003.88 \mathrm{f}$. Dissertação (Mestrado), UNESP-FCAV. Jaboticabal. 2003.

FRIZZONE, J. A.; GONÇALVES, A. C. A.; REZENDE, R. Produtividade do pimentão amarelo, Capsicum annum L., cultivado em ambiente protegido, em função do potencial mátrico de água no solo. Acta Scientiarum, Maringá, v.23, n.5, p.1111-1116, 2001.

HARTZ, T. K.; GIANNINI, C.; MIYAO, G.; VALENCIA, J.; CAHN, M.; MULLEN, R.; BRITTAN, K. Soil cation balance affects tomato fruit color disorders. Acta Horticulturae, n.487, p.49-55, 1999.

IPA, INSTITUTO AGRONÔMICO, DE PERNAMBUCO. Recomendações de adubação para o Estado de Pernambuco: $2^{\mathrm{a}}$. aproximação. Recife: IPA, 2008. 212 p.

ISHIKAVA, S. M. Olerícolas para cultivo em ambiente protegido. 2011. Disponível em: www.asbraer.org.br/arquivos/bibli/56-ca.produção.pdf. Acesso em: 20 setembro de 2018.

KROLOW, I. R. C.; FILHO, L. O.; MACHADO, J.; VITORIA, D. R.; MORSELI, T.; Cultivo do pimentão sob adubação orgânica em ambiente protegido. Horticultura Brasileira, Brasília, v.18, n.4, p. 597-601, 2004.

MORAIS, P. L. D.; DIAS, N. S.; ALMEIDA, M. L. B.; SARMENTO, J. D. A.; SOUSA NETO, O. N. Qualidade póscolheita da alface hidropônica em ambiente protegido sob malhas termorefletoras e negra. Revista Ceres, v. 58, n. 5, p. 407-410, 2011.

NANNETTI, D. C. Nitrogênio e potássio aplicados via fertirrigação na produção, nutrição e pós-colheita do pimentão. 2001. 184 f. Tese (Doutorado). Universidade Federal de Lavras, Lavras, 2001.

NEGRETTI, R. R. D.; BINI, D. A.; AMARAL, U.; MARTINS, C. R. Avaliação da adubação orgânica em pimentão Capsicun annum cultivado em sistema orgânico de produção sob ambiente protegido. Revista da Faculdade de Zootecnia, 
Veterinária e Agronomia, Uruguaiana, v. 17, n. 1, p. 27-37, 2010.

OLIVEIRA, A. N. P. de; OLIVEIRA, A. P. de; LEONARDO, F. de A. P.; CRUZ, I. da S.; SILVA, D. F. da. Yield of gherkin in response to doses of bovine manure. Horticultura Brasileira, Brasília, v. 27, n. 1, p. 100-102, 2009.

OLIVEIRA, F. A. Cultivo do pimentão em ambiente protegido utilizando diferentes manejos de fertirrigação. 2012. 222 f. Tese (Doutorado). Escola Superior de Agricultura "Luiz de Queiroz" - Universidade de São Paulo. Piracicaba, 2012.

RIBEIRO, L. G.; LOPES, J. C.; MARTINS FILHO, S.; RAMALHO, S. S. Adubação orgânica na produção de pimentão. Horticultura Brasileira, Brasília, v. 18, n. 2, p. 134137, 2000.

SANTOS, I. M. S. Manejos de irrigação para produção de pimentão em substratos agrícolas. 2015. 84p. Dissertação (Mestrado em Horticultura Irrigada) Universidade Estadual da Bahia, Juazeiro. 2015.

SEDIYAMA, M. A. N.; SANTOS, M. R.; VIDIGAL, S. M.; SALGADO, L. T.; PEDROSA, M. W.; JACOB, L. L. Produtividade e estado nutricional do quiabeiro em função da densidade populacional e do biofertilizante suíno. Bragantia, v.68, p.913-920, 2009.

SILVA, F. A. S. Assistat 7.5. UFCG, Campina Grande, 2013. ASSISTAT - Assistência estatística. Versão 7,5 beta, 2008.

SOARES, L. A. dos A.; LIMA, G. S.; CHAVES, L. H. G.; XAVIER, D. A.; FERNANDEZ, P. D.; GHEYI, H. R. Fitomassa e produção do girassol cultivado sob diferentes níveis de reposição hídrica e adubação potássica. Revista Brasileira de Engenharia Agrícola e Ambiental, v.19, p.336-342, 2015. http://dx.doi.org/10.1590/1807-1929/agriambi.v19n4p336-342.

UCHÔA, S. C. P.; IVANOFF, M. E. A.; ALVES, J. M. A.; SEDIYAMA, T.; MARTINS, S. A. Adubação de potássio em cobertura nos componentes de produção de cultivares de girassol. Revista Ciência Agronômica, v.42, p.8-15, 2011. http://dx.doi.org/10.1590/S1806-66902011000100002.

VIDIGAL, S. M.; SEDIYAMA, M. A. N.; PEDROSA, M. W.; SANTOS, M. R. Produtividade de cebola em cultivo orgânico utilizando composto à base de dejetos de suínos. Horticultura Brasileira, v.28, p.168-173, 2010. 